\title{
Microstructural characterisation of a collection of Protohistoric bronzes
}

\author{
E. Figueiredo***, R.J.C. Silva**, M.F. Araújo* and R. Vilaça***
}

*IST/ITN, Instituto Superior Técnico, Universidade Técnica de Lisboa, Estrada Nacional 10, 2686-953 Sacavém, Portugal

**CENIMAT/I3N, Departamento de Ciências dos Materiais, Faculdade de Ciências e Tecnologia, Universidade Nova de Lisboa, 2829-516 Caparica, Portugal

***CEAUCP-FCT, Instituto de Arqueologia, Departamento de História, Arqueologia e Artes, Faculdade de Letras, Universidade de Coimbra, Palácio de Sub-Ripas, 3000-395 Coimbra, Portugal

Microstructural characterisation of an archaeological collection of Protohistoric bronze artefacts attributed to around the VIII century B.C. and has been carried out using optical microscopy (OM) and scanning electron microscopy combined with energy dispersive spectroscopy (SEM-EDS). The collection was found in Medronhal cave (Condeixa-a-Nova, Portugal) and is composed by 1 fibula, 5 bracelets and 31 rings.

Small areas on the surfaces of the artefacts were cleaned from corrosion and were metallographically prepared by a manual polishing with several diamond suspensions in a cotton swab until 1 micron diamond size. OM observations were performed in bright field (BF) illumination and under polarized light (Pol), in unetched and etched conditions. SEM-EDS was performed without a conductive coating for a minimum external elemental interference.

OM observations allowed the study of the method and sequence of manufacture involved in the production of the various types of artefacts. Results show that the fibula and the bracelets have equiaxed (recrystallised) grain structures resulting from cyclic thermo-mechanical treatments performed to a pre-form cast bar until requested shape and surface finishing was attained. The rings, which are of diverse sizes, have various types of microstructures as a result of diverse manufacturing techniques. Some show a dendritic structure that resulted from the casting, and others show recrystallised structures that resulted from cycles of deformation and annealing procedures posterior to their casting (Figure 1).

SEM-EDS analysis allowed the study of the presence of inclusions in the metallic matrix and the study of corrosion in some artefacts (Figure 2). Different types of inclusions were identified, namely copper sulphides, tin oxide, and lead rich inclusions. Both copper sulphides and lead inclusions are commonly found in archaeological bronzes $[1,2]$, and can be a result of copper ores impurities. Tin oxide, on the other hand, is not so common, and its presence can be understood as a result of preferential oxidation of tin regarding copper during a melting or alloying operation [3]. The study of the interface alloy/corrosion showed the presence of chlorides in internal corrosion layers, which can probably be related to an aggressiveness of the burial environment.

\section{References}

1. Figueiredo E. et al., Mater. Manuf. Processes, 24:949, 2009.

2. Figueiredo E. et al., X-Ray Spectrom., 40:325, 2011.

3. Dungworth D., Bull. Met. Mus., 32:1, 2000. 

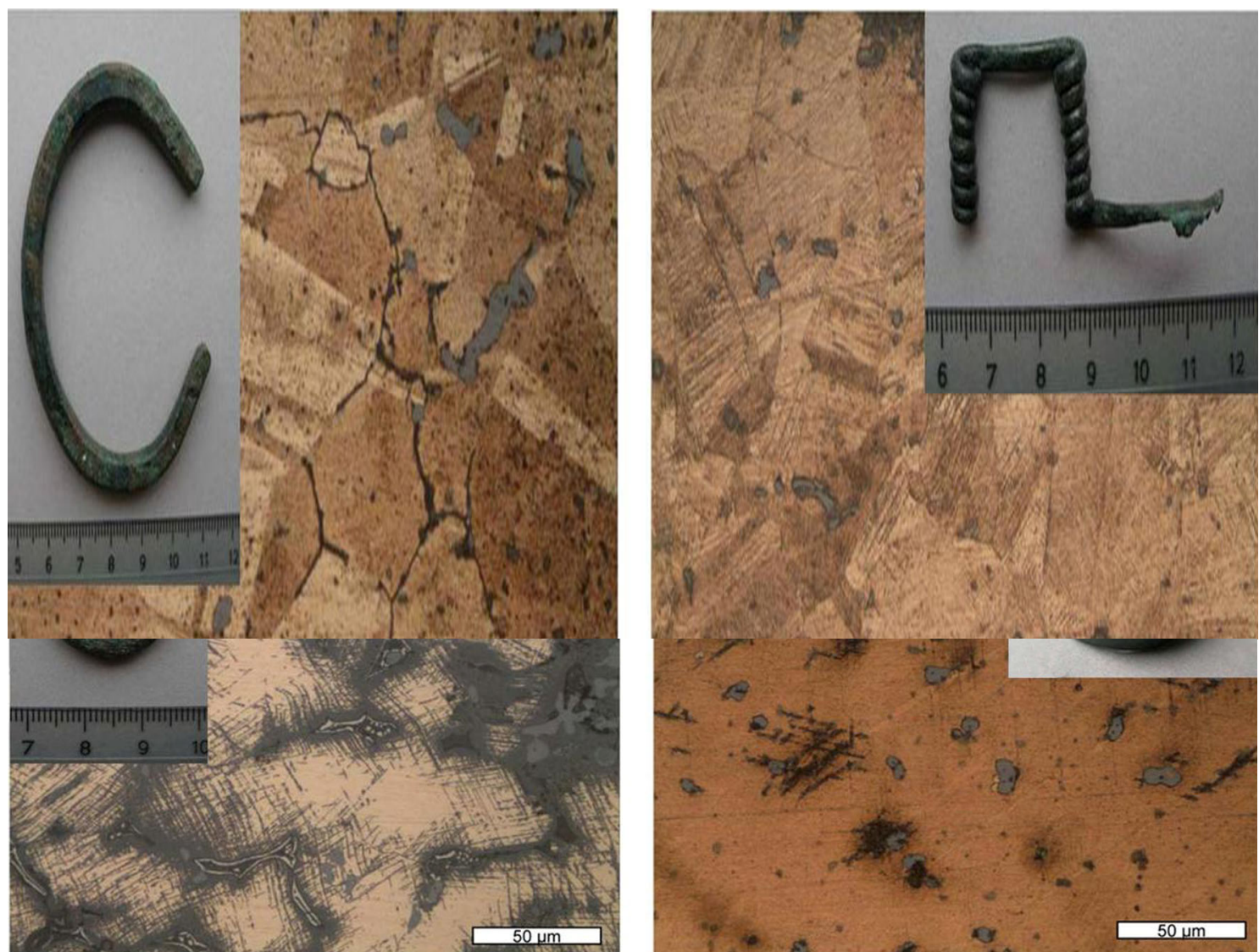

Figure 1. OM (BF) images of polished areas of various artefacts showing different microstructures as a result of diverse manufacturing techniques (from top left to bottom right: bracelet, fibula, and two rings with different shapes).
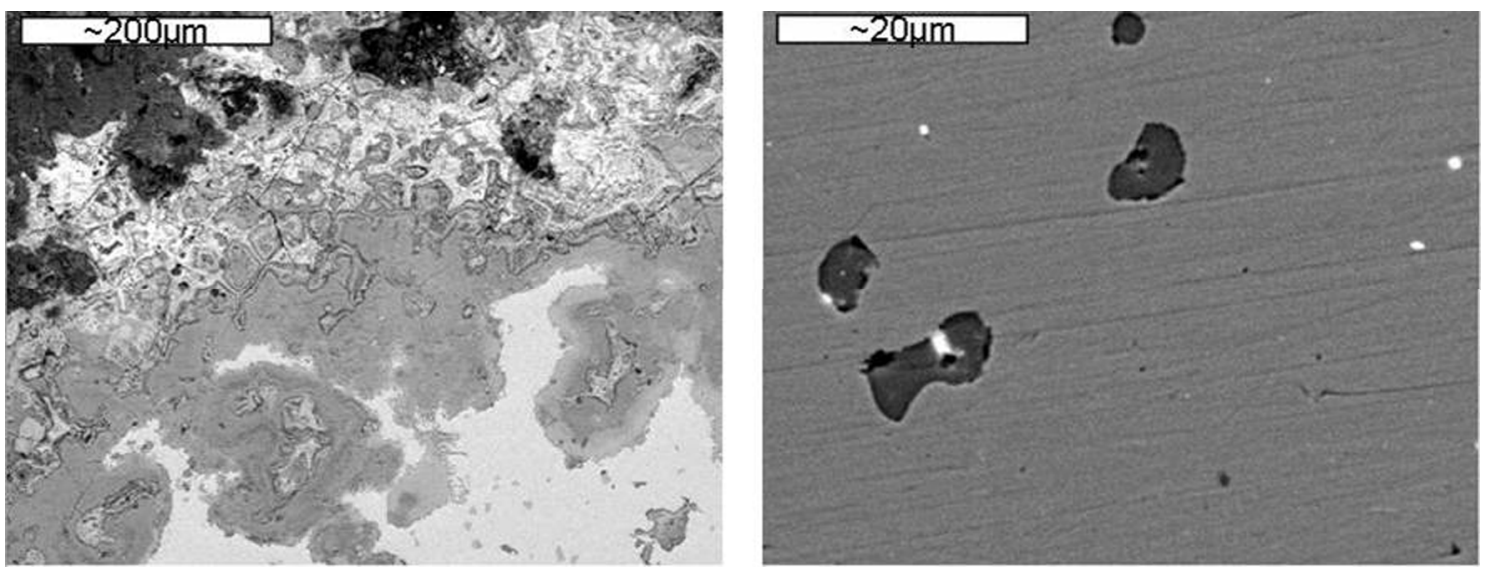

Figure 2. SEM (BSE) images of a polished area of a bracelet showing heterogeneous corrosion (left image) and inclusions in metal matrix (right image).

This research work has been financed by the Portuguese Science Foundation (FCT) through the EarlyMetal project (PTDC/HIS-ARQ/110442/2008), the grant SFRH/BPD/73245/2010 (to EF) and the Strategic ProjectLA25-2011-2012 (PEst-C/CTM/LA0025/2011) (to CENIMAT/I3N). 